\title{
Study of Surface Morphological, Phytochemical and Structural Characteristics of Rhodium (III) Oxide $\left(\mathrm{Rh}_{2} \mathrm{O}_{3}\right)$ Nanoparticles
}

\author{
A. Heidari", C. Brown \\ Faculty of Chemistry, California South University, 14731 Comet St. Irvine, CA 92604, USA \\ "Corresponding Author: E-Mail Address: Scholar.Researcher.Scientist@gmail.com
}

\begin{abstract}
Keywords: Rhodium (III) Oxide $\left(\mathrm{Rh}_{2} \mathrm{O}_{3}\right)$, Surface Morphology, PhytochemicalCharacteristics, Nanoparticles, X-Ray Diffraction (XRD), Attenuated Total Reflectance Fourier Transform Infrared Spectroscopy (ATR-FTIR), Scanning Electron Microscope (SEM)
\end{abstract}

\begin{abstract}
In the current research, Rhodium (III) Oxide $\left(\mathrm{Rh}_{2} \mathrm{O}_{3}\right)$ nanoparticles were produced in various sizes using ultrasonic waves and by adding various concentrations of linoleic acid as capping agent. Using X-Ray Diffraction (XRD) methods, phytochemical and structural characteristics of the produced samples were studied and the mean particle size was calculated by Debye - Scherer equation. The phytochemical characteristics of the produced nanoparticles were studied by Attenuated Total Reflectance Fourier Transform Infrared Spectroscopy (ATR-FTIR). The surface morphology of these structures shows that the Rhodium (III) Oxide $\left(\mathrm{Rh}_{2} \mathrm{O}_{3}\right)$ nanoparticles are formed in a spherical shape.
\end{abstract}

\section{INTRODUCTION}

In recent years, magnetic nanomaterials have been considered due to their applications in magnetic recording technologies. Rhodium (III) Oxide $\left(\mathrm{Rh}_{2} \mathrm{O}_{3}\right)$ nanoparticlesis one of these materials. Rhodium (III) Oxide $\left(\mathrm{Rh}_{2} \mathrm{O}_{3}\right)$ nanoparticlesis used in rechargeable batteries, gas sensors, catalyzers and magnetics [1-8]. Rhodium (III) Oxide $\left(\mathrm{Rh}_{2} \mathrm{O}_{3}\right)$ has two stable structural types $\left(\mathrm{RhO}_{2}, \mathrm{Rh}_{2} \mathrm{O}_{3}\right)$. The energy gap of $\mathrm{RhO}_{2}$ and $\mathrm{Rh}_{2} \mathrm{O}_{3}$ are between $1.9-2.3 \mathrm{eV}$ and 2.7-3.1eV, respectively [9, 10]. Characteristics of Rhodium (III) Oxide $\left(\mathrm{Rh}_{2} \mathrm{O}_{3}\right)$ nanoparticles are dependent to their size. Many phytochemical and structural characteristics of materials are varied by variation in their size. When colloid solutions remain for some time, smaller particles eliminate and remained particles enlarge. To control particle size, it is possible to make steric repulsion between nanoparticles using chemicals such as surfactants, organic compounds and polymers and hence, avoid agglomeration of nanoparticles [11-14].

In the current research, X-Ray Diffraction (XRD), Attenuated Total Reflectance Fourier Transform Infrared Spectroscopy (ATR-FTIR)and Scanning Electron Microscope (SEM) were used to study these compounds from morphological, structural and phytochemical points of view.

\section{TEST METHOD}

In the current study, Rhodium (II) acetate $\left(\mathrm{Rh}_{2}(\mathrm{AcO})_{4}\right)$ with $99 \%$ purity, Sodium hydroxide $(\mathrm{NaOH})$ with 99\% purity, ethanol and linoleic acid were used. To produce Rhodium hydroxide, 1.5 gr Rhodium (II) acetate $\left(\mathrm{Rh}_{2}(\mathrm{AcO})_{4}\right)$ and0.5gr Sodium hydroxide were solved in $35 \mathrm{ml}$ ethanol to produce 0.4 molar solution of each one. Then, Sodium hydroxide solution was added to Rhodium (II) acetate $\left(\mathrm{Rh}_{2}(\mathrm{AcO})_{4}\right)$ solution. Linoleic acid was used as capping agent to change particle size. In each step of test, a special amount of linoleic acid by $0,0.4 \mathrm{ml}, 0.8 \mathrm{ml}$ and $1.2 \mathrm{ml}$ concentrations was added. The resulting solution was subjected to ultrasonic waves for 75 minutes. Then, the solution was centrifuged and washed by distilled water for seven times and finally, the resulted precipitate was dried in vacuum. To produce Rhodium (III) Oxide $\left(\mathrm{Rh}_{2} \mathrm{O}_{3}\right)$, samples were placed in oven at $450^{\circ} \mathrm{C}$ for two hours. 


\section{RESULTS AND DISCUSSION}

Figures 1 and 2 show X-Ray Diffraction (XRD) spectrum of Rhodium (III) Oxide $\left(\mathrm{Rh}_{2} \mathrm{O}_{3}\right)$ nanoparticles with various concentrations of capping agent. As can be seen, the concentration of capping agent is effective in formation of Rhodium (III) Oxide $\left(\mathrm{Rh}_{2} \mathrm{O}_{3}\right)$ nanoparticles as well as particle size. By adding linoleic acid, other phases of Rhodium (III) Oxide $\left(\mathrm{Rh}_{2} \mathrm{O}_{3}\right)$ nanoparticles are formed and the width of peaks are increased. The mean crystallite size are calculated by Debye - Scherer equation.

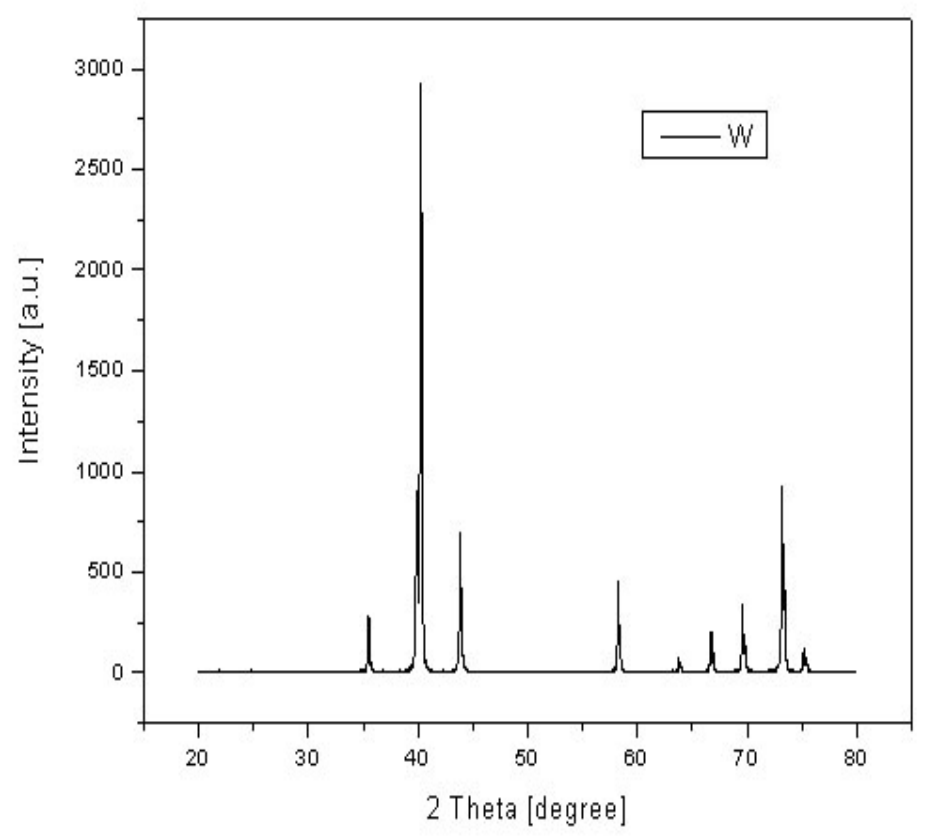

Figure 1. X-Ray Diffraction (XRD) spectrum of Rhodium (III) Oxide $\left(\mathrm{Rh}_{2} \mathrm{O}_{3}\right)$ nanoparticles without capping agent.

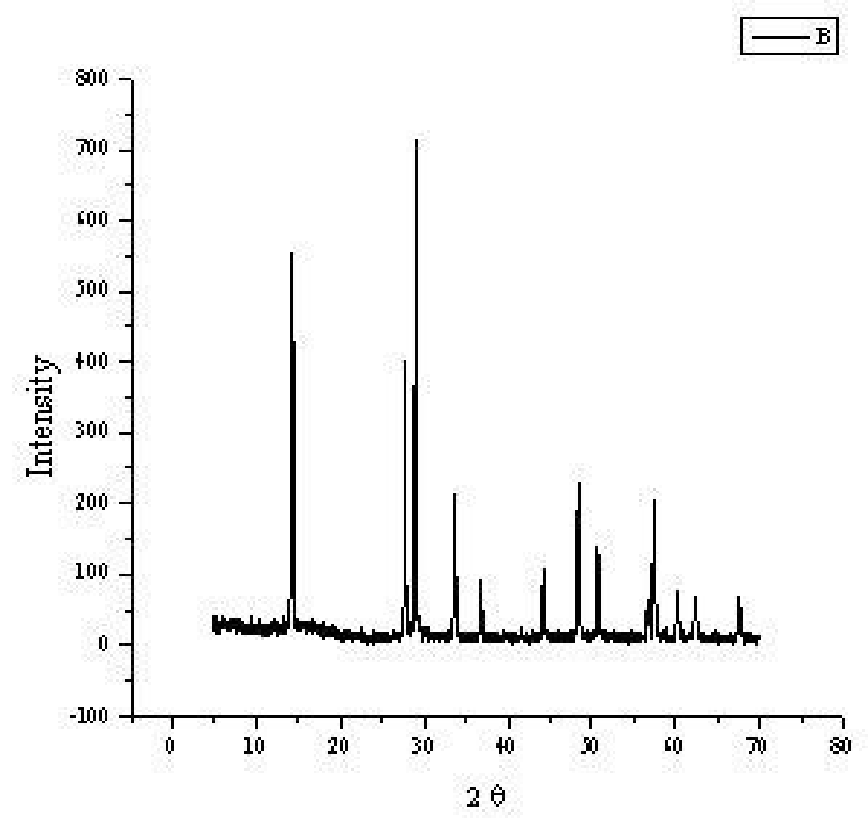

Figure 2. $\mathrm{X}$-Ray Diffraction (XRD) spectrum of Rhodium (III) Oxide $\left(\mathrm{Rh}_{2} \mathrm{O}_{3}\right)$ nanoparticles samples produced by various concentrations of linoleic acid. 
By increasing linoleic acid concentration, the absorption edge is shifted toward shorter wavelengths and shortening of absorption edge wavelength indicates the increase in energy gap and in fact, reduce in particle size. Figure 3 shows the results obtained from Attenuated Total Reflectance Fourier Transform Infrared Spectroscopy (ATR-FTIR).

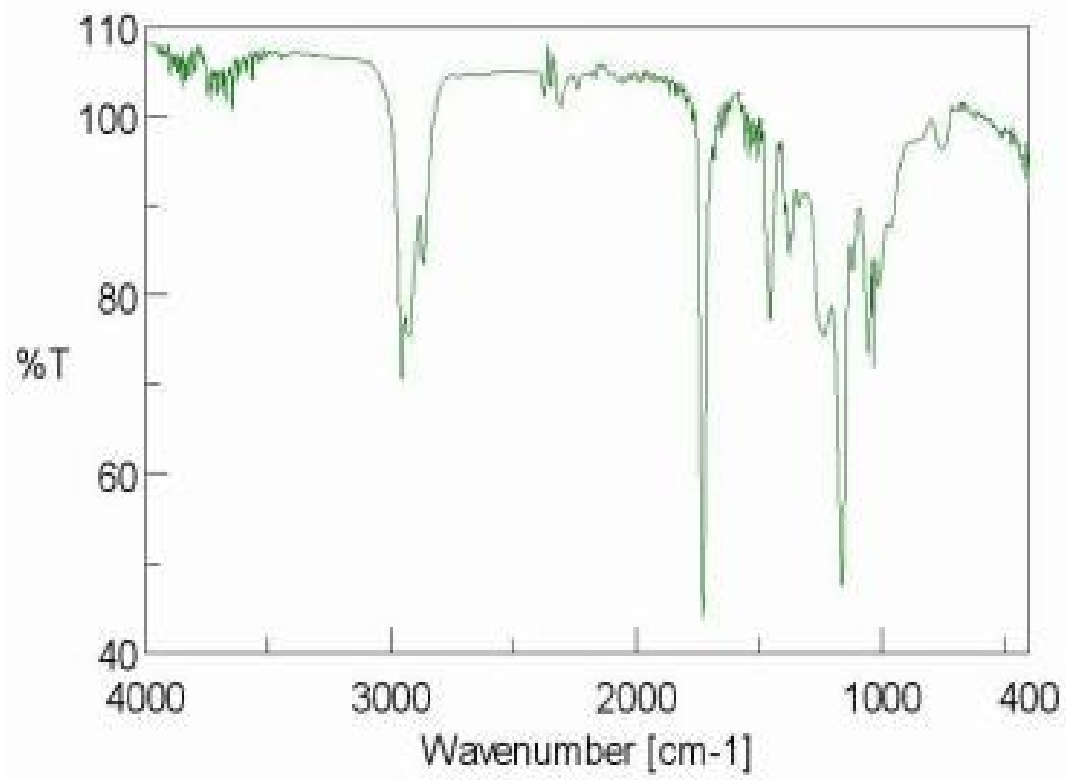

Figure 3. Attenuated Total Reflectance Fourier Transform Infrared Spectroscopy (ATR-FTIR) of Rhodium (III) Oxide $\left(\mathrm{Rh}_{2} \mathrm{O}_{3}\right)$ nanoparticles samples produced by various concentrations of linoleic acid.

The morphology of the produced samples were studied by Scanning Electron Microscope (SEM). Based on the comparison between Scanning Electron Microscope (SEM) images, it can be observed that although there are particles in nanometer size, the formed nanostructures are adhered together and they form a bulk structure when capping agent is not presented. Figure (4a) and (4b) are for Rhodium (III) Oxide $\left(\mathrm{Rh}_{2} \mathrm{O}_{3}\right)$ nanoparticles produced by increase in linoleic acid as capping agent. It is clear in the figures that by adding capping agent, nanoparticle size reduces. This is confirmed by X-Ray Diffraction (XRD) results. Furthermore, simulation of surface morphological characteristics of Rhodium (III) Oxide $\left(\mathrm{Rh}_{2} \mathrm{O}_{3}\right)$ nanoparticles were presented in Figure 5.
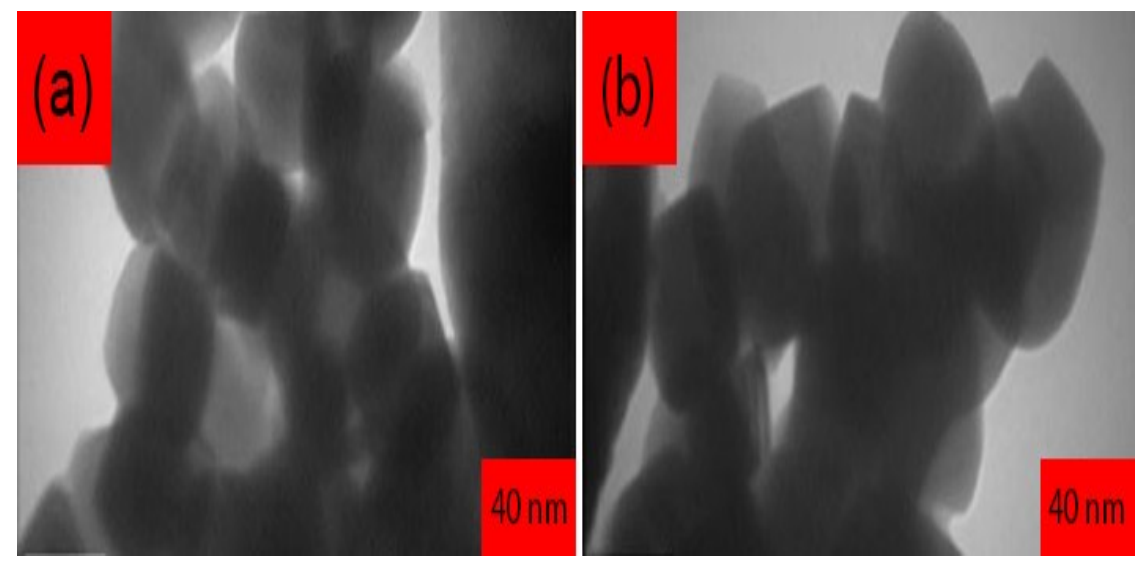

Figure 4. (a) Sample without linoleic acid and (b) Sample produced by adding $0.8 \mathrm{ml}$ linoleic acid. 

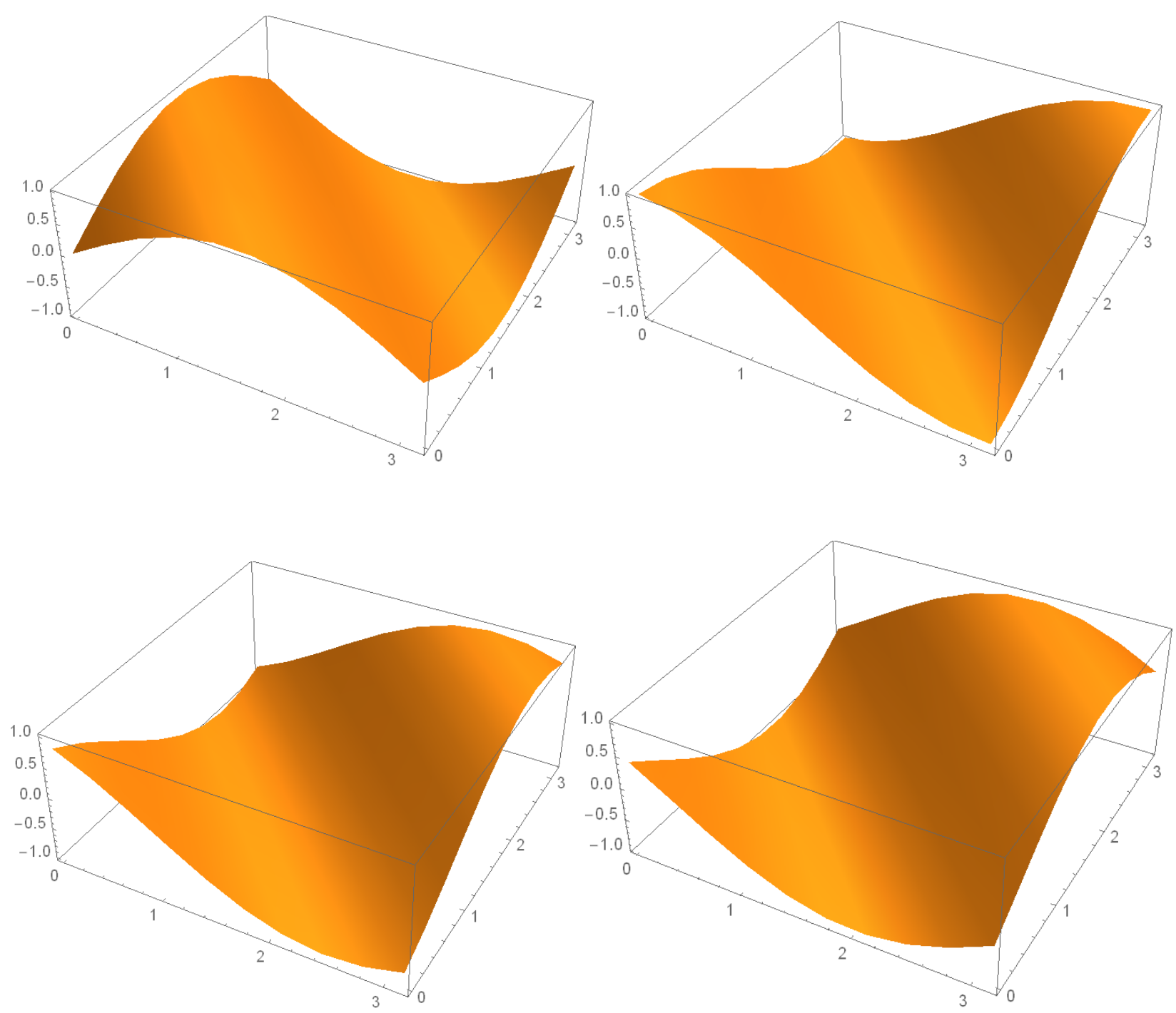

Figure 5. Simulation of surface morphological characteristics of Rhodium (III) Oxide $\left(\mathrm{Rh}_{2} \mathrm{O}_{3}\right)$ nanoparticles.

\section{CONCLUSION}

The Rhodium (III) Oxide $\left(\mathrm{Rh}_{2} \mathrm{O}_{3}\right.$ nanoparticles were produced using ultrasonic waves and by adding linoleic acid. The X-Ray Diffraction (XRD) results confirmed the effect of capping agent on formation of Rhodium (III) Oxide $\left(\mathrm{Rh}_{2} \mathrm{O}_{3}\right)$ nanoparticles and particle size. Attenuated Total Reflectance Fourier Transform Infrared Spectroscopy (ATR-FTIR) showed that energy gap of nanoparticles increased from $3.1 \mathrm{eV}$ to $5.3 \mathrm{eV}$. The surface morphology, phytochemistry and structure of these nanoparticles showed that they are adhered together and their size decreased by adding linoleic acid. 


\section{REFERENCES}

[1] Cinthia R. Zanata, Pablo S. Fernández, Horacio E. Troiani, Analía L. Soldati, Richard Landers, Giuseppe A. Camara, Adriana E. Carvalho, Cauê A. Martins, Rh-decorated PtIrOx nanoparticles for glycerol electrooxidation: Searching for a stable and active catalyst, Applied Catalysis B: Environmental, Volume 181, February 2016, Pages 445-455.

[2] Filippo Bossola, Claudio Evangelisti, Mattia Allieta, Rinaldo Psaro, Sandro Recchia, Vladimiro Dal Santo, Well-formed, size-controlled ruthenium nanoparticles active and stable for acetic acid steam reforming, Applied Catalysis B: Environmental, Volume 181, February 2016, Pages 599-611.

[3] Derya Özhava, Saim Özkar, Rhodium (0) nanoparticles supported on nanosilica: Highly active and long lived catalyst in hydrogen generation from the methanolysis of ammonia borane, Applied Catalysis B: Environmental, Volume 181, February 2016, Pages 716-726.

[4] Tamara Siqueira Moraes, Raimundo Crisostomo Rabelo Neto, Mauro Celso Ribeiro, Lisiane Veiga Mattos, Marios Kourtelesis, Spyros Ladas, Xenophon Verykios, Fábio B. Noronha, Ethanol conversion at low temperature over $\mathrm{CeO} 2$-Supported Ni-based catalysts. Effect of Pt addition to Ni catalyst, Applied Catalysis B: Environmental, Volume 181, February 2016, Pages 754-768.

[5] Alexander Joos, Christine Rümenapp, Friedrich E. Wagner, Bernhard Gleich, Characterisation of iron oxide nanoparticles by Mössbauer spectroscopy at ambient temperature, Journal of Magnetism and Magnetic Materials, Volume 399, 1 February 2016, Pages 123-129.

[6] Urmila Saxena, Asim Bikas Das, Nanomaterials towards fabrication of cholesterol biosensors: Key roles and design approaches, Biosensors and Bioelectronics, Volume 75, 15 January 2016, Pages 196-205.

[7] Sergey Kuklin, Anton Maximov, Anna Zolotukhina, Eduard Karakhanov, New approach for highly selective hydrogenation of phenol to cyclohexanone: Combination of rhodium nanoparticles and cyclodextrins, Catalysis Communications, Volume 73, 5 January 2016, Pages 63-68.

[8] Fan Liu, Yida Deng, Xiaopeng Han, Wenbin Hu, Cheng Zhong, Electrodeposition of metals and alloys from ionic liquids, Journal of Alloys and Compounds, Volume 654, 5 January 2016, Pages 163-170.

[9] Anne Giroir-Fendler, MairaAlves-Fortunato, Melissandre Richard, Chao Wang, Jose Antonio Díaz, Sonia Gil, Chuanhui Zhang, Fabien Can, Nicolas Bion, YanglongGuo, Synthesis of oxide supported LaMnO3 perovskites to enhance yields in toluene combustion, Applied Catalysis B: Environmental, Volume 180, January 2016, Pages 29-37.

[10] S. Rico-Francés, E.O. Jardim, T.A. Wezendonk, F. Kapteijn, J. Gascon, A. SepúlvedaEscribano, Enrique V. Ramos-Fernandez, Highly dispersed $\mathrm{Pt} \delta+$ on $\mathrm{TixCe}(1-\mathrm{x}) \mathrm{O} 2$ as an active phase in preferential oxidation of $\mathrm{CO}$, Applied Catalysis B: Environmental, Volume 180, January 2016, Pages 169-178.

[11] Jiawei Xia, Guangyu He, Lili Zhang, Xiaoqiang Sun, Xin Wang, Hydrogenation of nitrophenols catalyzed by carbon black-supported nickel nanoparticles under mild conditions, Applied Catalysis B: Environmental, Volume 180, January 2016, Pages 408-415.

[12] Vimal K. Jain, Rohit Singh Chauhan, New vistas in the chemistry of platinum group metals with tellurium ligands, Coordination Chemistry Reviews, Volume 306, Part 1, 1 January 2016, Pages 270-301.

[13] Ismar Borges de Lima, Chapter 19 - Rare Earths Industry and Eco-management: A Critical Review of Recycling and Substitutes, In Rare Earths Industry, edited by Ismar Borges De LimaWalter Leal Filho, Elsevier, Boston, 2016, Pages 293-304.

[14] Barry A. Wills and James A. Finch, Chapter 12 - Froth Flotation, In Wills' Mineral Processing Technology (Eighth Edition), edited by Barry A. WillsJames A. Finch, ButterworthHeinemann, Boston, 2016, Pages 265-380. 